\title{
VAGINAL DISCHARGES
}

\author{
Discussion on Mr. ALAN BREWS' PAPER
}

\section{CORRIGENDUM}

Mr. Ambrose KING added his own congratulations to those expressed by others on the excellence of this paper. $\mathrm{He}$ was interested in the remarks concerning the very great importance attached to the positive test and the relative uselessness of several negative tests and agreed that there was a good deal in the criticism. Nevertheless, it was necessary to realise the difficulties and uncertainties with which the venereologist was sometimes faced. It was a common experience to see women patients who had infected their consorts with gonorrhœa and themselves had signs of chronic infection, yet the gonococcus was not isolated by frequent and careful tests. His own view was that even in expert hands and under ideal circumstances the excellence of media for the cultivation of the gonococcus was subject to variations. The preparation of such media was an art which the pathologists had not yet fully mastered.

Naturally, Mr. Brews could not cover the whole of this big subject in the time available but he had made no mention of fungus infections of the vagina-the so-called "vaginal thrush." $\mathrm{He}$, the speaker, did not meet with this condition in venereal diseases practice and would be interested to know whether it was found in gynæcological clinics. He was interested, too, in the subject of senile vaginitis because in some of these cases it was possible to isolate the gonococcus from the secretions. He would be interested to hear Mr. Brews' opinion as to the possibility of the gonococcus being the causative factor in some of these cases. Another point on which he would like to hear the opener's views was the vexed question of the expediency of hysterectomy and removal of Fallopian tubes in the chronic stage of salpingitis. $\mathrm{He}$ asked whether Mr. Brews regarded that as a desirable procedure only in the presence of severe symptoms which were not 


\section{BRITISH JOURNAL OF VENEREAL DISEASES}

relieved by ordinary expectant methods of treatment or whether he considered it a good method of extirpating the infection when infectiousness persisted in spite of adequate local treatment.

[NOTE.-Through an unfortunate mistake the report of Mr. King's remarks on Mr. Brews' Address was allowed to go to press in an uncorrected form. This fact is greatly regretted by the co-Editor, who is solely responsible.E. R. T. C.] 